\title{
Relief from Back Pain Through Postural Adjustment: a Controlled Clinical Trial of the Immediate Effects of Muscular Chains Therapy (MCT)
}

\author{
Jose L. Rosario, PT, PhD \\ Department of Physical Therapy, State University of Center-West (UNICENTRO), Guarapuava, Brazil
}

\begin{abstract}
Introduction: Back pain can be one of the most common health problems, causing suffering, disabilities, and financial losses. Postural models for pain treatment state that poor posture alters the joint position and causes pain, such as back pain. Muscular Chain Therapy (MCT) is a technique that is used to treat posture pathologies, among others.
\end{abstract}

Purpose: The aim of the present study was to assess the efficiency of a single session of Muscular Chain Therapy (MCT) on complaints of undiagnosed musculoskeletal spinal pain.

Setting: Physical therapy clinic of the University of Center-West (Guarapuava, Brazil).

Participants: 100 subjects, aged between 20 and 39 years, with complaints of spinal musculoskeletal pain.

Research Design: Randomized controlled trial.

Intervention: The participants were randomly assigned by a non-care provider into two groups: The MCT Group that received Muscular Chain Treatment and the Control Group that received a placebo treatment of 15 minutes turned off ultrasound therapy. All volunteers were assessed before and after treatment using an analog pain scale. A score of 0 indicated no pain and 10 was the maximum degree of pain on the scale.

Main Outcome Measure: Degree of pain measured by analog scale

Results: The chi-square goodness of fit test was used to compare gender distribution among groups displayed a $p$ value $=.25$. Subject age had differences analyzed using the unpaired $t$ test $(p=.44)$. Pain assessment for treatment and placebo control groups was analyzed using a paired $t$ test and unpaired $t$ test. The paired $t$ test was used for intragroup before/after treatment comparison (MCT $p=.00001$; Control Group $p=.0001)$. The unpaired $t$ test was used for comparing the difference of the pain level before and after treatment between groups $(p=.0001)$. A priori statistical significance was set a $p=.05$.

Conclusion: It is possible to conclude that one MCT session is an effective treatment of undiagnosed spinal musculoskeletal pain.
KEY WORDS: posture; pain; analog pain scale; spine; musculoskeletal diseases; musculoskeletal manipulations; musculoskeletal pain; static stretching

\section{INTRODUCTION}

Back pain can be one of the most common health problems $^{(1)}$. As well as the suffering caused by pain and disability, a socioeconomic factor is also involved. Yearly, the total cost of this problem exceeds one-hundred billion dollars in the United States alone ${ }^{(2)}$. The same author stated that approximately $66 \%$ of the total cost is indirect (lost wages and reduced productivity).

Back pain can have several different causes ${ }^{(2)}$. Red flags, such as a tumor or spinal fracture, only cause between $1 \%$ and $4 \%$ of cases ${ }^{(3)}$. Currently, only a minority of patients are diagnosed ${ }^{(4)}$. The vast majority fall into the 'non-specific' musculoskeletal pain category ${ }^{(4)}$. This heterogeneity increases difficulty while researching the topic or treating patients. However, exercise therapy seems to be effective for chronic cases not related to red flags ${ }^{(5)}$. Postural models for pain treatment state that poor posture alters the joint position and causes pain ${ }^{(6,7)}$, which is more evident in a region with a high degree of mobility, such as the spine.

One of the postural models is based on the muscular chains therapy (MCT) concept. These chains are formed by anti-gravitational muscles that work synergistically in the same muscle or myofascial chain ${ }^{(8-10)}$. Therefore, a localized muscular action can provoke a reaction far from its origin. According to this concept, the structures forming a chain must be treated together ${ }^{(9,10)}$, stretching and strengthening several muscle groups simultaneously rather than simply treating an isolated muscle ${ }^{(9)}$.

Therefore, the aim of the present study was to assess the efficacy of a single application of Muscular Chain Therapy on complaints of undiagnosed musculoskeletal spinal pain.

\section{METHODS}

In total, 100 volunteers between 20 and 39 years old participated in the study at the Physical Therapy 
Clinic of the State University of the Center-West (Guarapuava, Brazil). The volunteers were recruited through a local newspaper advertisement. Inclusion criterion for the subjects was to have some selfreported spinal musculoskeletal pain. The exclusion criteria included any psychiatric or neurological disorders. Volunteers signed a statement of informed consent, and were assessed and treated with muscular chain therapy, as described by Rosario ${ }^{(11,12)}$, or placed in a placebo group. The present study received approval from the Human Research Ethics Committee of the State University of the Center-West UNICENTRO, under protocol number 289/2011.

The subjects were divided into two groups of 50 participants each: The MCT Group that received Muscular Chain Therapy and the Control Group that received a placebo treatment of 15 minutes ultrasound off therapy (UOT). Both groups were treated by a Physical Therapist with MCT certification. The randomization method consisted of 100 identically folded pieces of paper with MCT (50) or UOT (50) written in the internal part. All these pieces of paper were mixed in a bowl. After that, the subject picked up one of the papers to be assorted in the respective group. The subjects did not know the meaning of MCT or UOT. Every piece of paper was thrown out after being picked up by the volunteer.

\section{MCT Group Assessment and Comparison of Muscle Chains}

The assessment of the anterior and posterior chains, as described by Rosário ${ }^{(9)}$, were performed to find the most compromised muscular chain. The chain presenting the highest compensation was the first to be treated.

\section{MCT Treatment}

Treatment consisted of two postures of 20 minutes each. Before treatment, the subjects were taught how to separate breathing by region: apical, lower ribs, and diaphragmatic breathing, aimed at helping the maintenance of posture. The selection of posture was based on the assessment described above. If the therapist found more postural alterations in the posterior chain, two postures of the posterior chain were performed. If more deviations were found in the anterior chain, two postures of the anterior chain were performed. If the two chains exhibited similar deviations, the treatment included one posture for each chain. Both of the supine postures were performed according to Rosário $^{(9)}$.

\section{Ultrasound Off Therapy}

The subject, positioned in prone position, had 20 minutes of a placebo ultrasound therapy applied at the painful site. Gel was applied at the area of pain before the treatment. The setting of the $1 \mathrm{Mhz}$ ultrasound was $0.1 \mathrm{~W}$ pulse mode. The ultrasound transducer probe was always being slowly moved in circles and touching the skin of the volunteer. The subjects did not know it was a placebo therapy.

\section{Pain Assessment}

Pain is a symptom that accompanies the majority of pathological conditions that require medical care transversely. Among the internationally validated scales for measuring the intensity of pain, the ana$\log$ scale is one of the most utilized ${ }^{(8)}$. In the present study, a 10 centimeter line, scored from 0 to 10 , was shown to the subject, who verbally identified the degree of pain before and after the treatment, with zero indicating no pain and ten indicating the most intense pain possible.

\section{Statistical Analysis}

A chi-square goodness of fit test was used to compare gender distribution among groups. Subject age is presented as mean \pm standard deviation, with differences analyzed using the unpaired $t$ test. Pain assessment for treatment and placebo control groups was analyzed using a paired $t$ test and unpaired $t$ test. The paired $t$ test was used for intragroup before/after treatment comparison. The unpaired $t$ test was used for comparing the difference of the pain level before and after treatment between groups. A priori statistical significance was set a $p=.05$.

\section{RESULTS}

Table 1 displays mean and standard deviation for age and gender distribution in each group. Applying the Student's $t$ test for age resulted in a $p$ value $=$ .44. Using the chi-square test for gender comparison among the groups resulted in a $p$ value $=.25$. Thus, both groups were statistically similar.

Table 2 displays the number of times that each score (from zero to ten) was reported for all of the 50 spinal pain complaints of the MCT Group, before and after treatment.

Before the MCT session, the greatest number of complaints was between the values 3 to 8 . After the session, the majority of values were between 0 and 1 ,

TABLE 1. Mean and Standard Deviation for Age and Gender Distribution in Each Group: Muscular Chain Therapy (MCT) and Ultrasound Off Therapy (UOT)

\begin{tabular}{lccc}
\hline & Age & กे & ㅇ \\
\hline MCT & $31.2 \pm 6.7$ & 41 & 59 \\
UOT & $29.8 \pm 8.1$ & 39 & 61 \\
\hline
\end{tabular}


TABLE 2. Number of Times Each Value of the Analog Scale Was Reported in the 50 Complaints, Before and After One Session of Muscular Chain Therapy

\begin{tabular}{ccc}
\hline \multicolumn{3}{c}{$\begin{array}{c}\text { Amount of Occurrence of Each Value of the } \\
\text { Analog Scale }\end{array}$} \\
$\begin{array}{ccc}\text { Value on the } \\
\text { analog scale }\end{array}$ & $\begin{array}{c}\text { Before treatment with } \\
\text { MCT }(\mathrm{n}=50)\end{array}$ & $\begin{array}{c}\text { After treatment with } \\
\text { MCT }(\mathrm{n}=50)\end{array}$ \\
\hline 10 & 0 & 0 \\
9 & 2 & 0 \\
8 & 6 & 1 \\
7 & 7 & 0 \\
6 & 10 & 0 \\
5 & 12 & 1 \\
4 & 4 & 6 \\
3 & 7 & 4 \\
2 & 2 & 6 \\
1 & 0 & 14 \\
0 & 0 & 18 \\
\hline
\end{tabular}

with a significant number of complaints also found at value 2 and 4 of the scale. The no pain value (zero) increased from zero reports to seventeen, from the total of 50 complaints.

The mean of the 50 values before treatment was 5.52 , with a standard deviation of 1.80 . After treatment, these values dropped to a mean of 1.50 and a standard deviation of 1.72 . The number of complaints with some improvement was 48 , which is equal to $96 \%$ of cases. MCT had no effect in only one case $(2 \%)$; additionally, there was also one case (2\%) that worsened. The difference between the before and after averages is 4.02 . The significance of these data in the paired Student's $t$ test was $p=.00001$. Thus, it is possible to reject the equality between values before and after treatment.

Table 3 displays the values for 50 complaints of the Control Group.

Before the placebo session, the largest number of complaints was between the values 3 to 7 . After the session, the majority of values were between 3 and 6 . On the scale, the value of zero (no pain) increased from zero reports to one.

The mean of the 50 values before treatment was 5.50 , with a standard deviation of 1.86 . After treatment, these values dropped to a mean of 4.70 and a standard deviation of 2.09 . The number of complaints with some improvement was 18 , which is equal to $36 \%$ of cases. The placebo therapy had no effect in 29 cases $(58 \%)$ and, in three cases $(6 \%)$, the pain worsened. The difference between the before and after averages is 0.8 . The significance of this data in the paired Student's $t$ test was $p=.0001$. Thus, it is possible to reject the equality between values before and after treatment.
Table 3. Number of Times Each Value of the Analog Scale Was Reported in the 50 Complaints, Before and After One Session of Turned Off Ultrasound (Placebo)

\begin{tabular}{ccc}
\hline \multicolumn{3}{c}{$\begin{array}{c}\text { Amount of Occurrence of Each Value of the } \\
\text { Analog Scale }\end{array}$} \\
\hline $\begin{array}{c}\text { Value on the } \\
\text { analog scale }\end{array}$ & $\begin{array}{c}\text { Before treatment with } \\
\text { placebo }(\mathrm{n}=50)\end{array}$ & $\begin{array}{c}\text { After treatment with } \\
\text { placebo }(\mathrm{n}=50)\end{array}$ \\
\hline 10 & 0 & 1 \\
9 & 3 & 1 \\
8 & 5 & 4 \\
7 & 8 & 4 \\
6 & 9 & 6 \\
5 & 8 & 8 \\
4 & 8 & 10 \\
3 & 8 & 10 \\
2 & 1 & 5 \\
1 & 0 & 0 \\
0 & 0 & 1 \\
\hline
\end{tabular}

Comparing the values before the treatment between groups with the Student's $t$ test showed delta value of 0.009 and a $p$ value of .9. Therefore, it is not possible to reject the equality between the groups before treatment. Comparing the difference before and after treatment between the groups with the Student's $t$ test, the value of $p$ was .0001 (Table 4). The delta value, defined as the mean of difference scores across the two measurements, is equal to 3.22 .

The post hoc calculation for the power of sample was based in an effect size of 1.7, displaying a power of 1.0 .

\section{DISCUSSION}

Both groups showed significantly relief of undiagnosed spinal pain. The placebo had a $p$ value of .0001 and MCT .00001 after treatment. Comparing the groups, MCT was significantly better, with a $p$ value of 0.0001 . While the Control Group had a mean pain level of 5.50 before the treatment and

TABLE 4. Mean and Standard Deviation Before and After Treatment, Including Intergroup $p$ Value and $p$ Value Between the Groups

\begin{tabular}{lcccc}
\hline & $\begin{array}{c}\text { Mean and } \\
\text { Standard } \\
\text { Deviation } \\
\text { Before } \\
\text { Treatment }\end{array}$ & $\begin{array}{c}\text { Mean and } \\
\text { Standard } \\
\text { Deviation } \\
\text { After } \\
\text { Treatment }\end{array}$ & $\begin{array}{c}\text { Intergroup } \\
\text { Paired } \mathrm{t} \\
\text { Test, } \mathrm{p}\end{array}$ & $\begin{array}{c}\text { Between } \\
\text { Groups } \\
\text { t Test of } \\
\text { Change } \\
\text { Score, } \mathrm{p}\end{array}$ \\
\hline MCT Group & $5.52 \pm 1.80$ & $1.50 \pm 1.72$ & .00001 & \\
Control Group & $5.50 \pm 1.86$ & $4.70 \pm 2.09$ & .0001 & .0001 \\
\hline
\end{tabular}


4.70 after (a difference of 0.80 ), the mean pain level in the MCT Group was 5.52 before and 1.50 after (a difference of 4.02). MCT provided some pain relief in $96 \%$ of cases, whereas this figure was $36 \%$ in the Control Group.

A similar previous study conducted in our laboratory found that exercises using the concept of muscular chains were efficient in terms of decreasing nonspecific musculoskeletal pain in one session. However, the pain complaint could be located anywhere ${ }^{(12)}$. The present study focused on back pain. The spine has the contradictory functions of allowing a large range of movement while protecting the spinal cord. Normally, it has 33 vertebrae, nine of which are fused to form the sacrum and the coccyx. The remaining 24 are articulated vertebrae. Each vertebra articulates with the one below through two facet joints, which makes a total of 48 joints, not counting the atlantooccipital and sacroiliac joints. Adding complexity, there are the intervertebral discs and several muscles with different sizes and functions to control both small specific vertebral movements and large global spinal movements. All commands of the central nervous system pass through the spine (spinal cord), leaving it by the spinal roots. Consequently, it is not a surprise that back pain is a significant health concern ${ }^{(1)}$. It is considered the condition with the highest impact in terms of years lived with disability ${ }^{(13)}$. The previous study ${ }^{(12)}$ accepted any pain location. Because of the special characteristics of the spine, the effect of a postural exercise based on muscular chains could be different for back pain (better or worse). However, the findings are very similar, including the effects on the control group.

Back pain can be puzzling. It often seems to be more than just back pain. A survey study with more than 3,000 participants showed that just $16.8 \%$ of the respondents reported localized musculoskeletal pain $^{(14)}$. The majority felt pain in multiple places ${ }^{(14)}$. Another study reported back pain as being three times more prevalent in populations that have another chronic pain complaint ${ }^{(15)}$. The results of Rosario et al. ${ }^{(12)}$ are in accordance to these statements once many subjects exhibited more than one complaint. Comparing the previous data ${ }^{(12)}$ with the present it is possible to observe that, regardless of spinal biomechanical complexity, MCT seems to be as effective for back pain as it is for pain in other locations. This could be due to the characteristics of $\mathrm{MCT}$, which tends to work globally ${ }^{(9,11)}$.

Rosário et al. ${ }^{(16)}$ argue that this type of postural treatment technique does not act on posture simply by stretching. Their result has shown that a $15-\mathrm{min}-$ ute therapeutic posture provided similar hamstring flexibility as a 30-second hamstring stretch. Actively maintaining better joint positioning, reducing an existing subluxation, can exert influence on postural adjustment and, consequently, solve related pain ${ }^{(9)}$. The relief of $96 \%$ of the complaints, with a complete absence of pain in 18 of the 50 complaints, demonstrated the efficiency of MCT when properly applied.

Other authors have found positive results with this type of technique. Examples can be found in the work of Gil et al. ${ }^{(17)}$ who decreased back pain in pregnant women in eight weeks. Canto et al. ${ }^{(18)}$ stated that $85.7 \%$ of the participants reported a decrease in the level of back pain. Heredia and Rodrigues ${ }^{(19)}$ relieved the pain of patients with epidural fibrosis in postoperative lumbar disc herniation with 15 sessions, also using analog scales. These studies demonstrated how various causes of musculoskeletal back pain obtained positive results with this type of treatment, similar to the present study.

Another interesting result of the present study was the unexpected success of the placebo therapy, which was inferior to MCT, but still somewhat successful in achieving some pain relief in $36 \%$ of cases. These results corroborate the findings of other authors who suggested that the placebo effect occurs in $20 \%$ to $40 \%$ of the cases ${ }^{(20)}$. It seems that back pain is also associated with depression and anxiety ${ }^{(21)}$. Although it is not clear if depression and anxiety cause back pain or they are caused by back pain, they cannot be ignored. Thus, the emotional factor related to back pain and the emotional factor related to a subjective report of pain could also have contributed to the efficiency of the placebo treatment.

\section{CONCLUSION}

MCT was shown to reduce musculoskeletal back pain in young adult patients immediately post intervention. However, this study did not determine shortterm nor long-term effects of MCT. Further studies are required to verify the short- and long-term effect evaluation. Based on the immediate effects of MCT to reduce pain seen in this study, other pain syndromes that may be posturally based should be studied for the potential applicability of MCT. Objectives measures are also recommended for future works.

\section{CONFLICT OF INTEREST NOTIFICATION}

The authors declare there are no conflicts of interest.

\section{COPYRIGHT}

Published under the CreativeCommons AttributionNonCommercial-NoDerivs 3.0 License.

\section{REFERENCES}

1. Dreisinger TE. Exercise in the management of chronic back pain. Ochsner J. 2014;14(1):101-107. 
2. Katz JN. Lumbar disc disorders and low-back pain: socioeconomic factors and consequences. J Bone Joint Surg Am. 2006;88(Suppl 2):21-24.

3. Downie A, Williams CM, Henschke N, Hancock MJ, Ostelo $\mathrm{RW}$, de Vet HC, et al. Red flags to screen for malignancy and fracture in patients with low back pain: systematic review. BMJ. 2013;347:f7095.

4. van der Windt DA, Dunn KM. Low back pain research — future directions. Best Pract Res Clin Rheumatol. 2013;27(5):699-708.

5. Hayden JA, van Tulder MW, Tomlinson G. Systematic review: strategies for using exercise therapy to improve outcomes in chronic low back pain. Ann Intern Med. 2005;142(9):776-85.

6. Lee D. Principles and practices of muscle energy and functional techniques. In: Grieve GP, editor. Modern Manual Therapy of the Vertebral Column. New York: Churchill Livingstone; 1986.

7. Rosario JLP, Marques AP, Maluf AS. Aspectos Clínicos do Alongamento: uma revisão de literatura. Rev Brasil Fisioter. 2004;8(1):83-88.

8. Bailey B, Gravel J, Daoust R. Reliability of the visual analog scale in children with acute pain in the emergency department. Pain. 2012;153(4):839-42.

9. Rosario JLP, Nakashima IY, Rizopoulos K, Kostopoulos D, Marques AP. Improving posture: comparing segmental stretch and muscular chains therapy. Clin Chiropract. 2012;15(34):121-128.

10. Myers T. Anatomy Trains: Myofascial Meridians for Manual and Movement Therapists, 2nd ed. Edinburgh: Churchill Livingstone / Elsevier; 2009.

11. Rosario JLP. Efficiency of modified yoga positions to treat postural pathologies associated pain: a literature review. $J$ Yoga Phys Ther. 2012;2(6):128.

12. Rosario JLP, Orcesi LS, Kobayashi FN, Aun AN, Assumpção ITD, Blasioli GJ, et al. The immediate effects of modified Yoga positions for musculoskeletal pain relief. J Bodywork Movement Ther. 2013;17(4):469-474.

13. Vos T, Flaxman AD, Naghavi M, Lozano R, Michaud C, Ezzati M. et al. Years lived with disability (YLDs) for 1160 sequelae of 289 diseases and injuries 1990-2010: a systematic analysis for the Global Burden of Disease Study 2010. The Lancet. 2012:380(9859):2163-2196.
14. Kamaleri Y, Natvig B, Ihlebaek CM, Benth JS, Bruusgaard D. Number of pain sites is associated with demographic, lifestyle, and health-related factors in the general population. Eur J Pain. 2008;12(6):742-748.

15. Von Korff M, Crane P, Lane M, Miglioretti DL, Simon G, Saunders K, et al. Chronic spinal pain and physical-mental comorbidity in the United States: results from the national comorbidity survey replication. Pain. 2005;113(3):331-339.

16. Rosario JLP, Sousa A, Cabral CMN, João SMA, Marques AP. Reeducação postural global e alongamento estático segmentar na melhora da flexibilidade, força muscular e amplitude de movimento: um estudo comparative [in Portuguese]. Fisioter Pesqui. 2008;15(1):12-18.

17. Gil VFB, Osis MJD, Faúndes A. Lombalgia durante a gestação: eficácia do tratamento com Reeducação Postural Global (MCT) [in Portuguese]. Fisioter Pesqui. 2011;18(2):164-170.

18. Canto CREM, Oliveira LF, Gobbi FCM, Theodoro MN. Estudo da eficácia do metódo de reeduçação postural global em indivíduos com dor lombar com relação a dor e incapacidade functional [in Portuguese]. Ter Man. 2010;38(8):292-297.

19. Heredia EP, Rodrigues FF. O tratamento de pacientes com fibrose epidural pela reeducação postural global - MCT [in Portuguese]. Rev Brasil Neurol. 2008;44(3):19-26.

20. Verhulst J, Kramer D, Swann AC, Hale-Richlen B, Beahrs J. The medical alliance: from placebo response to alliance effect. J Nerv Ment Dis. 2013;201(7):546-552.

21. van der Windt DA, Dunn KM, Spies-Dorgelo MN, Mallen CD, Blankenstein AH, Stalman WA. Impact of physical symptoms on perceived health in the community. J Psychosom Res. 2008;64(3):265-274.

Corresponding author: Jose Luis Rosario, Physical Therapy department, University of Center-West, Rua Simeão Camargo Varela de Sá, 03 - Vila Carli, Guarapuava, Brazil

E-mail: ze.fisio@gmail.com 